\title{
Research on Problems and Countermeasures of 3D Printing Technology
}

\author{
Jiaofei Huo \\ XiJing University, shaanxi 710123 China \\ 95339323@qq.com
}

Keywords: 3D printing technology; Existing problems; Countermeasure analysis

\begin{abstract}
Since entering in twenty-first century, with the improvement of the social level, Chinese science and technology having also been a constant innovation, all walks of life in the process of the development have achieved of the reference advanced technology, among them, the 3D printing technology is one of the important emerging technologies in society. And with the continuous improvement of people's education concept, the society put forward higher requirements for the education of the country, but, many textbooks, handouts need some technology to print, which also promotes the development of 3D printing technology. However, due to the late start of 3D printing technology in China, compared with western developed countries, there being still a big gap in many aspects, so, in order to achieve the continuous progress of 3D printing technology, but also we need to continue to improve all aspects of the process in practice, thus, to ensure that the 3D printing technology to meet the needs of the development of society. Below, this article firstly introduces the definition of 3D printing technology, and then discusses the current stage of 3D printing technology problems, and finally gives the corresponding solutions.
\end{abstract}

\section{Introduction}

In recent years, with the improvement of the social level, many emerging technologies sweeping through the whole society, 3D printing technology is one of them. At present, 3D printing technology has made a greater contribution to the community, has been highly concerned about the community. Many people give 3D printing technology a high degree of evaluation, which is compared to the idea of twentieth Century, the nineteenth Century technology, and the market in twenty-first Century. Although the development process is more tortuous, and the growth process is relatively slow, but in demand of social development, 3D printing technology have developed into one of the necessary technology at this stage. Under such background, it is very important to develop and apply 3D printing technology to promote the development of society.

\section{D Printing Technology Introduction}

3D printing is a kind of printing technology formed in the end of twentieth Century which is one of rapid prototyping technology; Among them, the operation of the technology is based on the digital model file, and the materials used in the process of operation are generally some of the materials which can be bonded, Such as plastic materials, powdered metal and so on. And 3D printing technology is printing layer by layer. In the late ninety's of last century, there was no significant difference between the effect of the 3D printing technology and the general printing technology which is realized through the technology of light curing and paper lamination. And in the principle of printing, 3D printing technology and ordinary printing technology is no difference, when the printing system is running, Firstly, adding the liquid and powder materials into the printer's body, Then, connecting the printing equipment and the computer system to each other, and overlaying printing material layer by layer by the computer control, In the end, translating the image files on the computer into a kind material object. In daily life using the ordinary printers can print a computer graphic design and the working principle the so-called 3D printers and ordinary printers is basically the same. just in difference of printing materials, The printing material of the ordinary 
printer is ink and paper and the 3D printer equipped with metal, ceramic, plastic, sand and other different "printing materials", is a real raw material, After the printer is connected to the computer, through computer control, can make "printed materials" add layer upon layer, and finally realizing the entire operation process. And at present, after decades of development, 3D printing technology has been involved in various fields of social life widely used in jewelry, footwear, industrial design, architecture, engineering and construction (AEC), automotive, aerospace, dental and medical industry, education, geographic information system (GIS), civil engineering, guns and other areas .

\section{Analysis of the Development Status of 3D Printing Technology}

Technical Means Is Not Mature Enough. The biggest feature of 3D printing technology is the need to spend a long time, leading to a strong instability, so, at present, main technical problems of $3 \mathrm{D}$ printing industry is not mature products quality .because of needing a long time, 3D printing technology can only be applied to the production of personalized special products, and it is difficult to meet the needs of the public necessities of life which is because the production time consumption, making the production efficiency is greatly reduced, cannot be like the traditional printing of large-scale production in the form of mass production. And with the progress of society, people's demand for life is higher and higher, so the handicrafts, production parts and other products designed and produced by the current 3D printing technology may not be able to meet the needs of people. Next, 3D printing technology having higher requirements for raw materials in the process of printing, Not only need the material required to be accurately printed out, but also more important is that the print out of the product should meet the technical requirements. But at present, the row material of the 3D printing technology in China is very little, which has become an important factor restricting the rapid development of 3D printing technology.

3D Printing Industry Is Serious Lack of Professional and Technical Personnel. 3D printing technology is one of the industries that have developed rapidly in China since twenty-first Century, and through the development of recent years, has developed into an important factor affecting social life and through the development of recent years, has developed into an important factor affecting social life. The rapid development of 3D printing technology for professional talent demand is growing, and our country is serious lack of talent in this area at present. According to statistics, by 2014, Chinese enterprises engaged in 3D printing industry as high as several hundred, in these enterprises, the largest has thousands of people, the smaller or even only a few dozen people which have a common feature is serious lack of professional talent, even the small enterprise with on professional talent. Among them, the demand for Applied Talents in manufacturing is the largest, has reached as high as about 8000000 . 3D printing as a new enterprise, wanting to ensure its healthy and rapid development fundamentally, needs to develop set software optoelectronic technology, microelectronics, data technology and the integrated talent of rapid prototyping technology. What's more, our comprehensive personnel training in the 3D printing industry being also a lack of experience, many colleges and universities in our country haven't set up related professional of 3D printing technology, but also have not promoted the platform of the development of the theory and technical extension. Thus, our country's training for the 3D printing professional talent is far from the needs of social development, which is the important factor restricting the normal development of China's 3D printing industry.

The Development of 3D Printing Technology Market Is More Rapid, Higher Cost, More Difficult to Promote. 3D printing technology in China with a broad market for development, According to statistics, China's 3D printing industry in recent years, whose the annual output value is maintained at $30 \%$ growth rate, the growth rate of nearly $50 \%$ for two consecutive years 。 in many ways of printing, Desktop printing is one of the fastest forms of development, and the production value of desktop printers has exceeded 50\%, from the above data analysis, 3D printing industry has an important role in the development of the future society, but also has an infinite 
development potential. In recent years, more and more people seeing the advantages of 3D printing industry have committed to the development of this area, and many domestic enterprises have realized the overall production and sales. Currently on the market also increased the number of 3D printing experience stores, but by high-tech restrictions, it is difficult to all aspects of the development of 3D printing industry are applied in social life 3D printers. An important reason for this phenomenon is that our 3D printing technology has just started and the equipment and production materials in this area is still very short so it caused the scarcity of raw materials and the production of materials, resulting in high cost price, which is beyond the acceptable range of the general public, only in a number of large organizations or enterprises to be applied, and the general user and enterprise applications being few and less。 Thus, in production and manufacturing of $3 \mathrm{D}$ printing product, high cost is the biggest obstacle to the development of the market. Because our country has not formed the perfect production mode and the large scale effect, the production cost is difficult to control, coupled with the scarcity of materials, so that many printing materials can only rely on imports to maintain, resulting in a greater cost of materials, which is an important factor in the 3D printing industry is difficult to promote.

\section{Research on the Countermeasures of Promoting the Development of 3D Printing Technology}

Enterprises Should Increase the Power of Technical Research to Overcome Technical Problems. First of all, enterprises engaged in 3D printing should start with the existing technology, combining with the social status of the development of 3D printing in China, to develop a large data strategic appropriate for social development; Moreover, starting from the existing data, set the short-term development goals or stage of the big data strategic development goals, and then in accordance with the development of the strategy to ensure strict implementation of its scheduled target at each time period. Secondly, gradually establish and completely analysis system, in the process of development, according to the priorities of the business development, to achieve the continuous improvement of the relevant system, so as to realize the ability of data analysis in the sequential development, and then provide better support for the development of enterprises. Finally, in the establishment of a focus on product design and production management and other aspects of digital model, on this basis, the reasonable application of information integration system, and then realize the integration of the relevant data processing and analysis of the use of; At present, many 3D printing industry in China is a serious lack of digital model, so big data technology in Henan has been effectively applied, which is also an important reason to increase the strength of scientific research.

The Government Should Give Some Support to the 3D Printing Technology in the Capital and Policy. According to the survey, most of the enterprises eager to get the support of the government in policy or technology, only in the government's strong support, the industry can see the hope of progress. To this end, in the 3D printing industry, the government should play its due role in macroeconomic regulation and control, the specific practices as follows: First of all, the government should promptly integrate the data resources of the $3 \mathrm{D}$ printing industry. And the integration of 3D printing industry needs the effective combination of scientific research institutions, mechanism design, and third-party units. In this way, we And the government should allocate social resources effectively; The University's 3D printing research results quickly put into the production and application of enterprises, Step by step to form a deep level of inter professional multi field research cooperation system, and thus promote industrial development, promote regional economic growth can avoid the waste of resources caused by repetitive construction. Secondly, the government should vigorously promote the application of 3D printing technology in society. For any industry, the extension of the government is the fundamental driving force for promoting the development, and all enterprises should also timely response to the government's call, and vigorously promote the $3 \mathrm{D}$ printing technology, making more people understand the advanced $3 \mathrm{D}$ 
printing technology. Finally, in order to attract more people to invest in the development of the industry, the government can properly carry out tax relief, when it's necessary, can also be added in time for its R \& D funds. And the rapid development of Internet technology has provided a steady power for the development of 3D printing technology, to this end, the government should also vigorously support the application of Internet technology in the $3 \mathrm{D}$ printing industry, for the enterprises applying of the technology, should be appropriate to reduce their taxes, and thus promote the innovation and development of the business model. At the same time, the government should subsidize technology research and development expenses, which can mobilize the enthusiasm of enterprise independent innovation, promote technological innovation and business model innovation better and faster development.

Should Strengthen the Training of Talents in 3D Printing Industry. First of all, the government should put the professional talents in the field of 3D printing into the discipline construction system of higher education to train more professional talents for the industry. Especially the education institutions for graduated students in our country should pay more attention to the cultivation of technological innovation talents and the cultivation of innovative talents, to be able to develop more of the top level and professional talent. Secondly, vocational education in China's education also occupying a larger proportion, 3D printing technology should be in the vocational and technical schools to be open.

\section{Summary}

In a word, with the development of society level, 3D printing technology gets an ideal development. And with the continuous deepening of the various disciplines of society, 3D printing technology is bound to enter a new development situation. However, the development level of China's 3D printing industry is still relatively low, needing further development; so, it can make a greater contribution to the social development.

\section{The Educational Reform Subject Xijing University Planning.}

Serial number:GZJGGH1604

\section{References}

[1] Huang Jiaxiang, Li Guo zhang ,Pan Hong, Zhang Zhi yong, Chen Zhen ming, Ma Yan. The investigation and analysis of 3D printing technology in Guangdong colleges and universities to promote [J]. Labor security social. 2016 (05)

[2] Zhou Jiayong, Ji Ping xin, Mo Xin min, Zhang ang, Meng Xiaojing. Application and development trend of 3D printing technology in the military field [J]. Mechanical engineering and automation. 2015 (06)

[3] Li Shengnan, Xiong Huaping, Chen Bingqing, Li Neng, Li Wanqing. The microstructure and reaction mechanism of $\mathrm{Nb} / \mathrm{SiC}$ gradient materials are prepared by laser $3 \mathrm{D}$ printing method $[\mathrm{J}]$. Welding Journal (02) (2016).

[4] Shi Aihua, Zhang Hongke, Liu Shiqi, Jiang Nan, Tang Bo, Yang Lifei, Lu Yi. Application of $3 \mathrm{D}$ printing technology in the field of modern surgery $[\mathrm{J}]$. Clinical medical research and practice. $2016(02)$

[5] Yu Di, Yun shan, Yan Wei. Enhancing technology cooperates with the strength to create the future. 
[6] Yuan Zelin, Fang Hui, Huang Jigang, Zhang Wenjun, Xie Zhihao. Study on the precision influence factors and the fine tuning method of the 3D Kossel printer [J]. manufacturing technology and machine tools. 2016 (04)

[7] Pan Hui. Guangdong province to seize the development opportunity of 3D printing industry interview on China 3D printing technology industry alliance vice chairman, South China University of Technology professor Yang Yongqiang [J]. Guangdong science and technology. 2013 (19)

[8] He Hong, Lin Lin, Chen Juanjuan, Liao Shenghui, Song Ting, Yan Hao, Su Chunhong, Tan Yong, Chen Dunjin. Application value of 3D printing model in hysterectomy for patients with complicated placenta implantation [J]. Chinese Journal of Practical Gynecology and obstetrics. $2014(05)$

[9] Li Jian, Xu Min, by package.Disruptive technologies affecting the future: 3D printing with multi material mixture [J].Journal of Northeast Forestry University. 2015 (06)

[10]Zhou Jiayong, Ji Pingxin, Mo Xinmin, Zhang ang, Meng Xiaojing.Application and development trend of 3D printing technology in military field [J].Mechanical engineering and automation. 2015 (06) 